\title{
Como assim não estava no briefing? Novas perspectivas sobre o briefing no processo de design a partir da Teoria Ator-Rede
}

What do you mean that wasn't on the design brief? New perspectives about the brief in the design process through Actor-Network Theory lenses

\section{BATISTA, Marcelo Vianna}

Universidade do Vale do Rio dos Sinos - UNISINOS I mvianna@edu.unisinos.br

MEYER, Guilherme Englert Corrêa

Universidade do Vale do Rio dos Sinos - UNISINOS I gcmeyer@unisinos.br

\begin{abstract}
Resumo
Quando se trata do briefing, há um descompasso entre o que os estudos em design apontam a seu respeito e o que se postula sobre o processo de design. Enquanto briefing é entendido como algo que explicita e documenta os problemas, orientando o processo projetual, os estudos sobre processo de design apontam para um contexto difuso e nãolinear, orientado por dinâmicas adaptativas frente aos contextos que o design se propõe enfrentar sejam estes a geração de produtos e serviços ou estratégias organizacionais orientadas à inovação. Partindo da análise documental de 58 briefings, esta pesquisa procura compreender quem é o briefing em uso, como se materializa e quais processualidades the competem no processo de design. Para isto, princípios e conceitos da Teoria Ator-Rede permitem evidenciar a plasticidade de suas materializações e actancialidades evocativas que mediam o processo de projeto, em um caráter transformativo além do

\section{Abstract}

Regarding the design brief, there is a mismatch between what design studies posit about it and how the design process is, in fact, conducted. While the design brief is commonly understood as a tool to uncover problems and guide the development, design studies often describe a diffuse and non-linear design process that dynamically adapts to the work context - whether the objective is to design products/services or innovation-driven organizational strategies. From a documentary analysis of 58 design briefs sent by 6 informants, this research aims to broaden the understanding about the dynamics and procedures of the brief in the design process. Principles and concepts of the Actor-Network Theory informs on the plasticity with which the design brief is materialized. Even though it intends to simplify the development, the design brief evokes new perspectives for the design process, because it projects an otherwise restrictive approach onto the field of possibilities.
\end{abstract} normativo, situado na esfera das possibilidades.

Palavras-chave: Briefing. Processo de design. Teoria Ator-Rede.

Keywords: Design brief. Design process. Actor-Network Theory. 


\section{INTRODUĈ̣̃O}

Ao tratar dos processos de projeto os estudos em design compreendem ser impossível, na maioria dos casos, reduzi-los ao par problema-solução, pois isto incapacita o design em dar conta dos contextos que se propõe enfrentar. Tais contextos, adjacentes ao design como 'disciplina' fechada em si mesma, usam os expedientes do design para a projeção de sistemas produto-serviço, orientado à inovação organizacional (BUCHANAN, 2015; FINDELI, 2001). Neste sentido, formulam-se e desenvolvem-se estratégias com sentido e orientação majoritariamente adaptativo, uma vez que não se tem controle do ambiente externo ao se projetar (BUCHANAN, 2015; LAW, 1992).

O briefing, enquanto habitante no processo de projeto, é entendido no senso comum como recurso importante, documentando elementos necessários para explicitar o problema e orientar os envolvidos na ação projetual, sintetizando e disseminando necessidades entre os diversos atores. Mesmo que os estudos em design o compreendam como algo que gera diálogo (ZURLO, 2010), não restritivo ou vago demais (BROWN, 2009), que auxilia no enquadramento dos problemas (BUCHANAN, 1992) tornando, desta forma, o processo de projeto mais criterioso (ASSOCIAÇÃO DOS DESIGNERS GRÁFICOS DO BRASIL, 2004), tais concepções o colocam como uma etapa de síntese, que não acompanha as movimentações teóricas sobre o processo de projeto. Haveria outras processualidades que ultrapassem este senso comum e aproximem o briefing da esfera em que os estudos em design olham para o processo de projeto?

Para tratar a questão, esta pesquisa recorre à Teoria Ator-Rede (TAR)' entendendo que sua proposta teórico-metodológica pode contribuir no entendimento acerca das materializações do briefing e as relações estabelecidas nas dinâmicas de projeto as quais participa. A TAR postula não haver distinção entre humanos e não-humanos na construção de fatos e artefatos, sendo impossível apontar empiricamente diferenças entre suas actancialidades ${ }^{2}$ (CALLON, 1984; LATOUR, 1987; LAW, 1992) - todos são entendidos como

1 Em inglês usa-se o acrônimo ANT para Actor-Network Theory, porém opta-se nesta pesquisa por usar o acrônimo em português - TAR - daqui por diante.

2 Actancialidade, enquanto conceito embebido na TAR, significa as ações possíveis de acontecer ou que acontecem, geradas independente do ator ser humano ou não-humano - opõem-se a noções clássicas de que competência é algo humano e que não-humanos tem funcionalidades. Ver mais em Law (1999). 
actantes $^{3}$ que se associam em uma rede sociotécnica4 (LATOUR, 1999), em movimento contínuo, mediando ${ }^{5}$ a emergência de questões de preocupação (LATOUR, 2008) e pontualizando ${ }^{6}$ interesses em torno de estabilizações (LAW, 1992) que façam sentido. Considerando "conceitos suficientemente resistentes para aguentar a viagem por essas disciplinas, esses períodos e objetos" (LATOUR, 1987, p. 35-36) a TAR permite olhar as dinâmicas estabelecidas entre actantes de forma simétrica - sem determinismos humanos ou técnicos - expandindo a compreensão do briefing e como o próprio processo, envolvido em um processo aberto e adaptativo, movimenta-se em direção a estabilização em torno de um fato ou um artefato.

A partir da análise documental de 58 suportes entendidos como briefing por 6 informantes de escritórios de design ou empresas com departamento de design, são delineados quem são os briefings em uso a partir de como se materializam e do que participam nos processos de projeto, ou seja, quais processualidades participam.

Nas seções a seguir serão apresentadas compreensões sobre briefing e processo de projeto nos estudos em design, conceitos sensibilizantes da TAR e suas contribuições para compreender o briefing no âmbito desta pesquisa, o método adotado para análise dos briefings e os resultados gerados - expressos nos quadros analíticos desenvolvidos pelos autores e, por fim, discussões finais os resultados obtidos.

3 Actante representa o esforço da TAR em superar a dicotomia entre humano e nãohumano e o deterministo humano presente no termo 'Ator'. Será melhor tratado na seção 3.

4 O termo 'sociotécnico', para TAR, é uma rede de elementos materiais e imateriais, onde os conhecimentos tecnocientíficos são indissociáveis das associações humanas e não-humanas. Uma 'rede sociotécnica' se configura, portanto, como uma esfera onde os conhecimentos tecnocientíficos são indissociáveis das associações sociais e técnicas, e são frutos da construção de um coletivo: "somos animais sociotécnicos, e toda interação humana é sociotécnica. Jamais estamos limitados a vínculos sociais. Jamais nos defrontamos unicamente com objetos." (LATOUR, 1987, p. 245).

5 O conceito de intermediação e mediação, na TAR, tratam das transformações que actantes operam nas associações ocorridas em torno de um fato ou artefato. Será melhor tratado na seção 3 .

6 Pontualizado é um conceito trazido por Law (1992) que representa a simplificação operada frente a fatos e artefatos, evitando dar conta da sua complexidade (e.g. não nos preocupamos com tudo o que compõe enquanto hardware e software um computador, apenas usamos o sistema). Pode ser compreendido como uma rede que se transforma em ator, em uma rede maior. 


\section{OS ESTUDOS DO DESIGN EM RELAC̣ÃO AO BRIEFING E AO PROCESSO DE PROJETO}

No senso comum, o briefing é entendido como um componente importante em qualquer projeto por conter elementos necessários para orientar os envolvidos na ação projetual. Em dicionários, como MerriamWebster, briefing é um substantivo definido como "um ato ou etapa que fornece instruções precisas, ou informações essenciais." (BRIEFING, 2016a). Já no Oxford Dictionaries define-se como "1. Uma reunião em que se passam instruções ou informações; 2. A ação de informar ou passar instruções para alguém." (BRIEFING, 2016b). Em ambas definições, o briefing é uma ação de dar instruções ou informar claramente, ou seja, tem um caráter orientativo em que não parece haver espaço para trocas - o que é posto deve ser seguido. Há também diferenças em alguns aspectos descritos por ambos dicionários: Para o Merriam-Webster pode ser uma etapa de algo, um momento que parece específico, com início e fim, preciso (sem margens de interpretação) ou essenciais (sem os quais não se começa a etapa), enquanto para o Oxford Dictionaries amplia-se um pouco, podendo ser uma reunião. (BRIEFING, 2016b).

No campo dos estudos do design, Zurlo (2010) amplia ainda mais ao trazer o conceito de 'contrabriefing', compreendido como uma resposta crítica a um briefing recebido, ou seja, envolve um momento de crítica ao que está posto. Zurlo (2010) acrescenta também que mais do que sintetizar necessidades ao tornar explícito objetivos, necessidades e obrigatoriedades, o briefing opera um diálogo entre o design e os atores envolvidos no projeto. Em Brown (2009) o briefing é compreendido também como uma etapa que não podem ser nem tão objetiva, inibindo a capacidade dos designers de ter ideias, nem tão aberta, a ponto de deixá-los 'perdidos no escuro'. Por si só o ato de fazer design é um ato que envolverá um briefing: segundo a Associação dos Designers Gráficos do Brasil (2004) para fundamentar um processo de projeto e torná-lo mais criterioso, qualificando o resultado final do trabalho, é preciso haver um briefing. Para Buchanan (1992), o briefing não representa apenas uma definição dos assuntos de interesse de um projeto em particular, ele trata dos problemas a serem enfrentados, trazendo à tona uma lista de questões que devem ser consideradas. Em situações em que o briefing especifica detalhadamente como deve ser o projeto e qual o resultado, assim o faz porque o autor ou responsável pela construção do briefing tenta transformar o problema em uma hipótese plausível, numa tentativa de minimizar seu caráter wickedness ${ }^{7}$ - situação nem sempre bem-sucedida dada a natureza pouco determinável da maioria dos problemas enfrentados pelos projetos de design. 
Porém, apesar de tais colocações presentes nos estudos do design contribuírem ao acrescentar aspectos fundamentais do briefing como a importância do diálogo entre os atores envolvidos (ZURLO, 2010), a importância de não ser restritivo ou vago demais (BROWN, 2009), sua fundamentalidade em tornar o projeto criterioso (ASSOCIAÇÃO DOS DESIGNERS GRÁFICOS DO BRASIL, 2004), auxiliando ao posicionar e reposicionar questões sobre o problema, revelando hipóteses sobre o que se deve explorar (BUCHANAN, 1992), tais discussões parecem não contemplar dinâmicas estabelecidas pelo briefing no processo de projeto.

Os estudos em design situam as discussões em outra esfera, de temporalidade difusa, não linear, com dinâmicas adaptativas. Segundo Findeli (2001), é preciso compreender o design como ciência 'envolvida', 'situada' ou 'integrada', entendendo que os processos de projeto demandam atitude similar à do próprio questionamento científico: como algo conduzido (e não 'aplicado'), ou seja, do questionamento e da reflexão na prática se constroem os conhecimentos do design, assim como estes conhecimentos, postos em prática, geram artefatos de design. Neste sentido, o processo de projeto é concebido como um sistema que se modifica e se altera, sendo que designers, usuários e todos os demais atores - o briefing, inclusive - envolvidos também são parte de sistema, em alteridade constante em uma "[...] nova lógica estrutural do processo de projeto que (1) ao invés do problema tem o estágio $\mathrm{A}$ de um sistema; (2) ao invés de uma solução, tem o estágio B do sistema; e (3) o designers e usuários são partes do sistema." (FINDELI, 2001, p. 10).

O problema não seria visto como algo a ser definido em etapas iniciais ou encontrado ao longo do processo, mas como uma pergunta desvencilhada de uma solução. Livre de encontrar respostas comuns e validações, torna-se espaço capaz de encontrar acordos e responder as inquietações, necessidades e interesses amplos que o próprio processo de projeto faz emergir. Com atores engajados por essa abertura, o contexto projetual passa a ser um espaço aberto e evolução, unindo social e técnico em um sistema de operação não focado em ser otimizado e eficiente, mas que permita emergir novas condições, interações e relações (BJÖRGVNISSON; EHN; HILLGREN, 2010). Tratando de questionamentos fundamentais para emergência de interesses, o processo de projeto passa a ser entendido como algo impossível de ser conduzido ou aplicável, fortalecendo sua natureza não-linear em que não contam com um problema definido, mas como "estágio de um sistema que se modifica e se altera" como aponta Findeli (2001).

Neste sentido, a compreensão sobre o briefing está situada em um modelo que compreende o processo de projeto como linear - o briefing como é entendido está situado na etapa inicial do projeto, em que há um problema definido. Na ótica do processo de projeto entendido como não-linear, em que o problema não é bem definido, aparentemente o briefing não é capaz de acompanhar o processo e os problemas que precisa dar conta. Neste 
sentido, pode-se afirmar que as discussões sobre o briefing parecem não ter acompanhado as mudanças discutidas nos próprios estudos de design no que tange o processo de projeto e a caracterização do problema.

É desejável uma ampliação sobre quem é o briefing em direção a uma atuação mais relevante, indo além de discussões sobre o que sintetiza ou dissemina: é necessário compreender sobre as dinâmicas que lhe competem no processo de projeto, buscando por um novo olhar sobre quem ele é.

\section{TEORIA ATOR-REDE E AS CONTRIBUIC̣ÕES AO DESIGN}

Na busca por esta ampliação sobre quem é o briefing, há aspectos compreendidos até aqui, quanto às aparentes dinâmicas que estabelece no processo de projeto, que encontram nos Estudos da Ciência, Tecnologia e Sociedade $(\text { ECTS })^{8}$, em específico a TAR, construto teórico capaz de auxiliar nos interesses desta pesquisa.

A aproximação entre os estudos em design e a TAR não é novidade: alguns autores encontram em Latour o ponto de partida para esta aproximação (STORNI, 2015), outros apontam que as bases estão na tradição dos ECTS e a relação direta com o campo do design no que tange superar a dicotomia existente entre ciências sociais e tecnológicas (BINDER et al., 2015), entre outros. No design participativo há boas mostras do interesse em relacionar a TAR e o design, com destaque para o periódico CoDesign que, em 2015, publicou uma edição especifica sobre o tema. Oscilando entre perspectiva teórica (em graus diversos de apropriação), metodologia, framework ou a adoção de conceitos específicos, a TAR tem emergido nas discussões do campo do design principalmente pela não dicotomização entre humanos e não-humanos, em sintonia com os estudos atuais do design que compreende a irredutibilidade do artefato a um papel secundário na construção social9 .

$\mathrm{Na}$ abordagem da TAR, a análise das dinâmicas sociotécnicas baseiam-se na equivalência entre atores humanos e não-humanos, no que toca as relações de: 1) igualdade, seguindo a ordem de importância e valor para uma rede sociotécnica ao invés de determinismos, seja humano ou seja técnico; 2) implicação recíproca, ou seja, há dificuldade em apontar empiricamente diferenças entre os agenciamentos humanos e não-humanos

8 Em inglês usa-se o acrônimo STS para Studies in Science, Technology and Society, porém opta-se nesta pesquisa por usar o acrônimo em português - ECTS - daqui por diante.

9 Os autores desta pesquisa desenvolveram uma análise sistemática para as palavraschave 'Actor Network Theory' e 'design' nas bases de dados EBSCOhost. A partir da leitura dos 137 artigos disponíveis, foram selecionados 15 artigos relevantes para compreender como se aproximam ambos os campos. Este material gerou um artigo, ainda não publicado. 
e 3) complementaridade, impossibilitando separar as implicações técnicas no cotidiano das sociedades, assim como o caminho oposto. (CALLON, 1984; LATOUR, 1999, 2005). Seguindo a TAR, nesta pesquisa entendemos o briefing enquanto um ator 1) de posição simétrica a dos humanos; 2) que, portanto, tem papel de mediador; 3) e que estabiliza as dinâmicas de projeto.

Para atingir uma equivalência imparcial entre humanos e não-humanos, a TAR adota o termo actante por compreendê-lo como "algo que atua ou aquele que faz o outro fazer [...] sendo qualquer coisa que provê ou é capaz de ser uma fonte de ação" (LATOUR, 1996, p. 373), pois o termo opõe-se a noção clássica da sociologia sobre ator social ser um humano. Segundo Latour (1999, p. 346), "a palavra ator se limita a humanos, [por isso] utiliza-se muitas vezes actant [actante], termo tomado da semiótica, para incluir não-humanos na definição". O uso de actante representa um esforço da TAR em justamente eliminar determinismos humanos e incluir os não-humanos na compreensão de social e nas competências de agenciamento, e será utilizado daqui por diante nesta pesquisa para o tratamento do que, até então, tratava-se como atores humanos e não-humanos. É a partir da adoção de actante que, na visão dos autores desta pesquisa, muda-se o foco para ações e de onde vem, em simetria.

A compreensão de social também assume outro significado na TAR. Analisando a etimologia da palavra social, Latour (2005, p. 6) afirma que seu significado é SEGUIR: "o latim socius denota uma companhia, uma associação". Socius não está relacionado ao humano, mas sim as associações e a movimentação gerada nas dinâmicas sociotécnicas, sendo o social um "[...] tipo de associação momentânea, caracterizada pela maneira como se reúnem as novas formas" (LATOUR, 2005, p. 65), sendo esta reunião de formas efeitos de intermediações e mediações dos actantes.

O conceito de intermediação e mediação, na TAR, tratam das transformações que actantes operam nas associações ocorridas em torno de um fato ou artefato. O que difere os conceitos é que intermediação compreende haver uma imutabilidade do actante, enquanto mediação predispõe que ele também se modifica nas associações (SAYES, 2014). Tomando-se este conceito, fica difícil imaginar que alguma ação aconteça ou algum saber seja executado sem que haja uma mediação que inclua os não-humanos, contribuindo claramente na expansão da leitura sobre o briefing no processo de projeto.

$\mathrm{Na} T A R$, o conceito de mediação equaliza as ideias clássicas de sujeito e objeto, trazendo ambos para a mesma arena, enfrentando as mesmas dificuldades. Mediação compreende que as dificuldades dos actantes nesta equalização de sujeito e objeto se explicitam em questões de preocupação ${ }^{10}$ múltiplas, que vão além dos interesses diretamente relacionados ou explícitos.

10 Adota-se esta tradução para 'matters of concern' por compreendê-la capaz de representar bem o sentido usado pelos autores originais. 
(LATOUR, 2008). Compreender questões de preocupação demanda de o pesquisador/observador entender que as agências dos actantes não tem um único objetivo, mas sim reúnem muitos objetivos, removendo a divisão entre "social" e "natural":

“[...] um mundo natural composto de questões de fato não parece em nada com um mundo que consiste de questões de preocupação, logo não pode ser usada tão facilmente para desenrolar a ordem social que prega o 'simbólicohumano-intencional" (LATOUR, 2008, p. 114).

Para chegar às questões de preocupação é preciso olhar para as incertezas, abrindo a capacidade interpretativa do que é constituído como 'fato'. Diferente da compreensão de 'múltiplos pontos de vista', a compreensão de questões de preocupação representa que o objeto investigado em si permite-se perceber como múltiplo, isto é, não tem uma força interna nem externa, mas forças circulares e associativas dependendo do contexto em que está inserido. (LATOUR, 2008). Fatos tendem a se manter imutáveis, enquanto preocupações se expandem em respostas que são fluídas. Pela própria construção científica pende-se em direção a buscar fatos, uma vez que fatos fornecem algo tangível e pontualizado. O que preconiza a TAR é o caráter mediador e agenciador dessa materialidade, que ao invés de estática é dinâmica e apresentada em controvérsias emergentes (vistas, por exemplo, em um laboratório de pesquisa). (LATOUR, 2008).

A materialidade, em si, ganha outra definição na TAR, pois deixa de ser apenas um dado, uma coisa ou um fato alocado em uma determinada situação e passa a ser questão de preocupação, por seus atributos mais dinâmicos e ativos (LATOUR, 2008), o que leva a compreensão do caráter mediador dos actantes, ou seja, eles constantemente se modificam e modificam seus interesses nas associações as quais fazem parte, por mais que hajam esforços de reduzir seus interesses.

Neste sentido, compreender o briefing reduzido ao que está exposto exclusivamente pela sua materialização pontualizada - ou seja, pelo que materializa nas fases iniciais do projeto - não é suficiente para compreender quem ele é. A redução do descompasso entre ele e o que se discute sobre processo de projeto pede que seja entendido enquanto um actante, com actancialidades de mediação - seguindo neste percurso, atingem-se outras compreensões a seu respeito.

\section{MÉTODO E RESULTADOS}

Os autores desta pesquisa realizaram a Análise Documental 58 briefings enviados por 6 informantes que se denominam escritórios de design 
ou 'empresas com departamento de design'. A aproximação, via e-mail, utilizou a rede de relações dos autores, que circularam profissionalmente entre escritórios de design de diversos segmentos. Intencionalmente os autores optaram por chamar o briefing de 'suporte', evitando reduções típicas do senso comum caso chamassem de documento, o que demonstrou eficiente uma vez que tal movimento abriu discussões no processo de coleta.

A escolha pela Análise Documental responde diretamente a natureza do objeto de pesquisa, o problema posto e a perspectiva teórica dos autores, que operaram um tipo de arqueologia sobre as informações coletadas a partir de investigação, exame, manuseio e utilização de técnicas e procedimentos específicos para organização, extraindo conteúdo que permitisse analisar e elaborar sínteses (SÁ-SILVA; ALMEIDA; GUINDANI, 2009). Adotou-se também a Análise de Conteúdo como forma de instrumentalizar esta Análise Documental. Para Krippendorff (2012, p. 24), a Análise de Conteúdo é uma técnica de pesquisa interessada em alcançar inferências válidas e replicáveis de textos. Nesta pesquisa optamos pelo processo descrito por Moraes (1999), envolvendo 1) Preparação das informações, em que se (a) identificam e (b) codificam as amostras de informação a serem analisadas; 2) Unitarização ou transformação do conteúdo em unidades, que passa pela (a) definição e (b) isolamento das unidades de análise, bem como pela definição das unidades de contexto; 3) Categorização ou classificação das unidades em categorias, de modo que sejam elas válidas, exaustivas e homogêneas; 4) Descrição, em que se comunica o material das categorias e; 5) Interpretação, interessada uma compreensão mais aprofundada do conteúdo das mensagens.

Descreve-se, a seguir, os suportes recebidos, numerados para efeito de codificação das informações. Opta-se por uma descrição reduzida em virtude dos espaços do artigo, e por acreditar que tal descrição é suficiente para ilustrar esse procedimento de pesquisa.

O único suporte encaminhado pelo Informante \#1 foi um texto estruturado como um questionário, esclarecido como "uma forma de garantir que tudo o que se precisa saber sobre um projeto é perguntado." Os 41 suportes enviados pelo Informante \#2 foram registros fotográficos de seu caderno, que esclareceu a lógica explicando que, por ser um escritório pequeno, o briefing é os desenhos e os escritos no caderno, que ele e os demais envolvidos acessam quando necessário. Os 3 suportes enviados pelo Informante \#3 foram textos completos, preenchidos. Os 4 suportes enviados pelo Informante \#4 também foram textos completos, mas é curioso destacar a defensiva do porta-voz do escritório que além do sigilo, informou que os materiais enviados eram "só uma parte do briefing, que havia muitos combinados feitos pessoalmente, anotados no briefing ou enviados por e-mail ao longo do processo dos projetos e que não eram documentados." Quando os autores solicitaram que fossem enviados tais suportes, o escritório disse que o que interessava era aquilo que fora enviado, contradizendo-se (ou demonstrando falta de tempo ou 
de paciência). O Informante \#5, por sua vez, demonstrou-se interessado na pesquisa, convidado os autores para irem ao seu escritório. Neste encontro, cuidados foram mantidos em se ater ao mínimo de informações possíveis, rendendo 7 suportes distintos entre si: 5 registros fotográficos de cadernos, um texto identificado como estrutura usada para trabalhos simples e rápidos e uma planilha com resumos dos trabalhos em andamento no escritório. Por fim, o Informante \#6 enviou 2 suportes: printscreens de um sistema de gestão e um e-mail. Assim como o informante \#3, destacou que há mais suportes usados e reforçou que na sua opinião o papel do briefing é 'de gerir o projeto' (mesmo que tal pergunta não tinha sido efetuada). Mesmo que estas compreensões, genéricas e não previstas pelo método, não reflitam na análise de conteúdo e si, são extremamente relevantes para os autores porque revelam um primeiro aspecto de como o briefing se apresenta: plural, envolto em interpretações subjetivas.

Figura 1 - Representação da pluralidade de suportes recebidos.

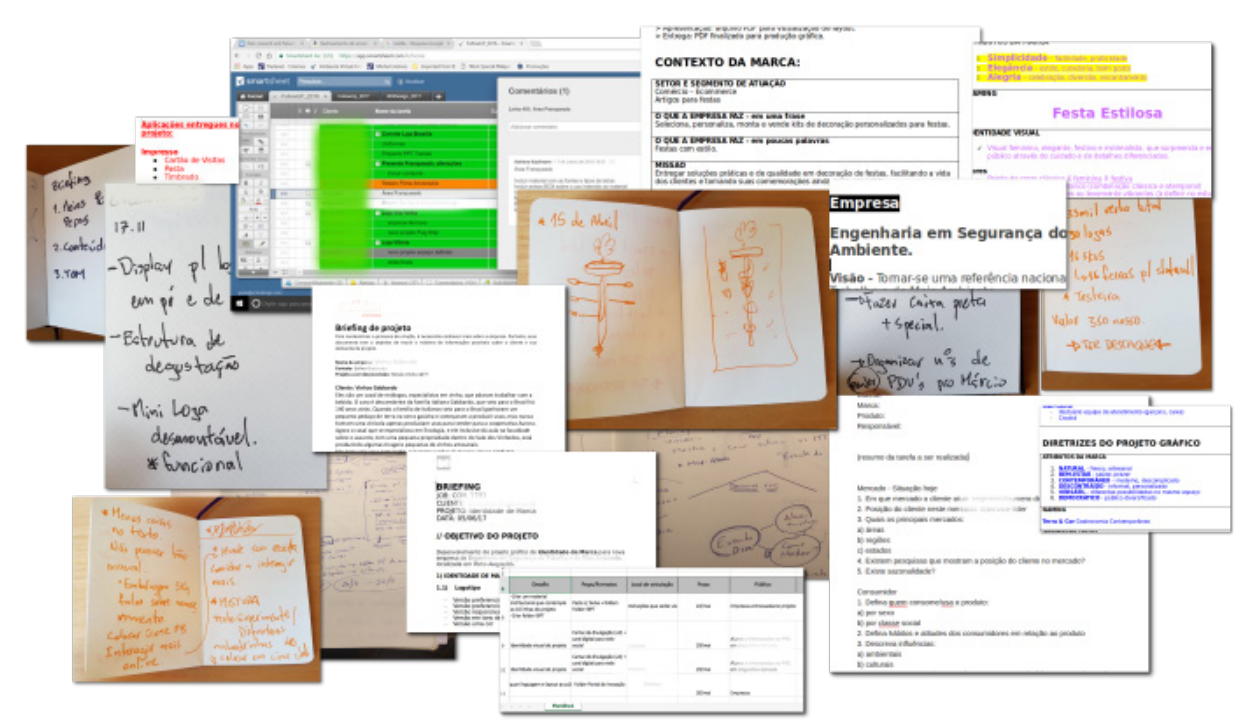

Fonte: Elaborado pelos autores.

Diferente de uma Análise de Conteúdo de suportes textuais, a preparação das informações envolveu a transcrição e interpretação desta pluralidade de briefing, inviabilizando uma transposição de sua forma 'imagem' para texto. Neste artigo, os autores optam por contingenciar no movimento de zoom in deste contexto, que é 'plano e determinado pelo fluxo' (LATOUR, 1999). Isto é, esta primeira análise dos autores gerou um quadro analítico sobre as materialidades do briefing (zoom out), porém neste artigo será tratado apenas o quadro intitulado 'Informações', desenvolvido a partir da leitura do que o briefing - o zoom in que trata das suas actancialidades. Este recorte, necessário por questões de adequação ao tamanho do artigo, deixa fora também um outro método adotado (dois grupos focais com actantes que usam briefing), mas que os autores pretendem publicar em breve. 
Iniciando a análise do quadro 'Informações', a organização gerou as seguintes categorias: 1) 'Orientações gerais'; 2) 'Grau de imprescindibilidade'; 3) 'Problema'; 4) 'Objetivos'; 5) 'Atores'; 6) ‘Especificações técnicas' e 7) 'Síntese', tratadas em detalhe a seguir.

Quadro 1 - Esquematização do quadro 'Informações'.

\begin{tabular}{|c|c|c|}
\hline Categoria & Subcategoria & Unidade e origem \\
\hline \multirow{8}{*}{$\begin{array}{l}\text { 10rientações gerais } \\
\text { Informações que } \\
\text { tratam de aspectos } \\
\text { amplos }\end{array}$} & \multirow{3}{*}{$\begin{array}{l}\text { 1.1 Contextualização } \\
\text { mercadológica } \\
\text { Relacionados } \\
\text { ao mercado e o } \\
\text { contexto de atuação } \\
\text { do demandante do } \\
\text { projeto. }\end{array}$} & $\begin{array}{l}\text { Para conduzirmos a criação, é necessário } \\
\text { conhecer mais sobre a empresa. (i4s4) }\end{array}$ \\
\hline & & Mercado em que o cliente atua. (i1s1) \\
\hline & & $\begin{array}{l}\text { Devemos colaborar para que o mercado total } \\
\text { aumente nos primeiros } 6 \text { meses em .........\%? } \\
\text { (i1s1) }\end{array}$ \\
\hline & \multirow{3}{*}{$\begin{array}{l}1.2 \text { Considerações } \\
\text { criativas } \\
\text { Relacionado a } \\
\text { orientações criativas }\end{array}$} & $\begin{array}{l}\text { Pensar bem nas poses }(\ldots) \text { procuraram } \\
\text { [nome da marca considerada referência] } \\
\text { sem calço }(\ldots) \text { cuidar logo }(\ldots) \text { (i2s } 8)\end{array}$ \\
\hline & & $\begin{array}{l}\text { (...) pensei em colocar a safra no selo que vai } \\
\text { por cima da capsula no gargalo da garrafa. } \\
\text { (i4s1) }\end{array}$ \\
\hline & & $\begin{array}{l}\text { Visual feminino, elegante, festivo e } \\
\text { minimalista, que surpreenda e encante o } \\
\text { público através do cuidado e de detalhes } \\
\text { diferenciados. (i3s2) }\end{array}$ \\
\hline & \multirow[t]{2}{*}{$\begin{array}{l}\text { 1.3 Ideias propostas } \\
\text { Relacionados a ideias } \\
\text { explícitas }\end{array}$} & $\begin{array}{l}\text { Foi cogitado desenhar na arte da caixa, uma } \\
\text { "Estrada" ou "Caminho" em curva, com } \\
\text { vários objetos antigos e novos, por exemplo } \\
\text { um (...) Telefone antigo e celular, TV antiga e } \\
\text { computador. (i4s4) }\end{array}$ \\
\hline & & $\begin{array}{l}\text { "esta franquia não dá dor de cabeça" é fácil - } \\
\text { conceito para produzir um remédio contra os } \\
\text { concorrentes de franquias difíceis. (i6s1) }\end{array}$ \\
\hline \multirow{7}{*}{$\begin{array}{l}2 \text { Graus de } \\
\text { imprescindibilidade } \\
\text { Informações que } \\
\text { tratam do que deve } \\
\text { ser feito, em graus } \\
\text { de normativos } \\
\text { diferentes }\end{array}$} & \multirow{2}{*}{$\begin{array}{l}\mathbf{2 . 1} \text { Importante } \\
\text { O que precisa } \\
\text { ser levado em } \\
\text { consideração }\end{array}$} & $\begin{array}{l}\text { É importante não usar imagens } \\
\text { "estereotipadas" de idosos (...). (i4s4) }\end{array}$ \\
\hline & & $\begin{array}{l}\text { Precisamos colocar benefícios que [o } \\
\text { cliente] proporciona para os franqueados, } \\
\text { treinamento contínuo; suporte criativo no } \\
\text { projeto, implementação e execução da loja } \\
\text { (...). (i6s1) }\end{array}$ \\
\hline & \multirow{2}{*}{$\begin{array}{l}\text { 2.2 Obrigatório } \\
\text { O que deve ser feito }\end{array}$} & Textos obrigatórios. (i1s1) \\
\hline & & $\begin{array}{l}\text { Vamos escrever no rótulo [marca do cliente]. } \\
\text { (i4s1) }\end{array}$ \\
\hline & \multirow{3}{*}{$\begin{array}{l}\text { 2.3 Limitações } \\
\text { O que não pode ser } \\
\text { feito }\end{array}$} & Limitações e obrigatoriedades (i5s1) \\
\hline & & Existem restrições? (i1s1) \\
\hline & & $\begin{array}{l}\text { Quais os pontos negativos que devem ser } \\
\text { evitados? (i1s1) }\end{array}$ \\
\hline \multirow{2}{*}{\multicolumn{2}{|c|}{$\begin{array}{l}3 \text { Problema } \\
\text { Informações que explicitam o 'problema' }\end{array}$}} & Cenário/problema. (i5s1) \\
\hline & & $\begin{array}{l}\text { Problema: precisamos pensar em que tipo } \\
\text { de peças de comunicação podemos produzir } \\
\text { para venda de franquia [nome do cliente]. } \\
\text { (i6s1) }\end{array}$ \\
\hline \multirow{2}{*}{\multicolumn{2}{|c|}{$\begin{array}{l}4 \text { Objetivos e expectativas } \\
\text { Informações que explicitam 'objetivo' e } \\
\text { 'expectativa' }\end{array}$}} & $\begin{array}{l}\text { Objetivo: expansão do mercado franchising } \\
\text { das lojas físicas da [marca do cliente] (...). } \\
\text { (i6s1) }\end{array}$ \\
\hline & & $\begin{array}{l}\text { Quais as expectativas do cliente em relação } \\
\text { a campanha e cada peça? (i1s1) }\end{array}$ \\
\hline
\end{tabular}




\begin{tabular}{|c|c|c|}
\hline \multirow{7}{*}{$\begin{array}{l}5 \text { Actantes } \\
\text { Informações que } \\
\text { expressam a quem } \\
\text { o briefing advoga } \\
\text { como porta-voz, } \\
\text { componentes da rede } \\
\text { sociotécnica }\end{array}$} & \multirow{2}{*}{$\begin{array}{l}\text { 5.1 Responsável } \\
\text { Quem originou o } \\
\text { projeto }\end{array}$} & Responsável. (i1s1) \\
\hline & & Responsável pelo pedido. (i5s1) \\
\hline & \multirow{3}{*}{$\begin{array}{l}\text { 5.2 A quem se } \\
\text { destina o fato ou } \\
\text { artefato } \\
\text { Para quem se projeta }\end{array}$} & $\begin{array}{l}\text { Defina hábitos e atitudes dos consumidores } \\
\text { em relação ao produto (i1s1) }\end{array}$ \\
\hline & & $\begin{array}{l}\text { Quem vai receber esse material é o público ( } \\
\text { ) interno ( ) externo. (i5s1) }\end{array}$ \\
\hline & & $\begin{array}{l}\text { O público alvo é prioritariamente masculino, } \\
\text { porém amplo - dos diretores das empresas } \\
\text { aos operadores de máquinas. (i3s1) }\end{array}$ \\
\hline & \multirow[t]{2}{*}{$\begin{array}{l}\text { 5.3 Terceiros } \\
\text { Quem mais está } \\
\text { envolvido no projeto }\end{array}$} & $\begin{array}{l}\text { A gráfica que imprime as peças é a [nome } \\
\text { empresa] de São Paulo, e o contato é o } \\
\text { Luciano. (i4s4) }\end{array}$ \\
\hline & & $\begin{array}{l}\text { Benchmark: The TomKat Studio, Mog \& } \\
\text { Mug, Lia Griffith e HWTM. (i3s2) }\end{array}$ \\
\hline \multirow{9}{*}{$\begin{array}{l}6 \text { Especificações } \\
\text { técnicas } \\
\text { Informações que } \\
\text { escrutinam o projeto }\end{array}$} & \multirow{3}{*}{$\begin{array}{l}\text { 6.1 Detalhamento } \\
\text { Caraterísticas formais } \\
\text { e quantidades do que } \\
\text { se espera do projeto }\end{array}$} & $\begin{array}{l}\text { Quais as peças que devem ser } \\
\text { desenvolvidas, quais as especificações } \\
\text { técnicas e formatos? (i1s1) }\end{array}$ \\
\hline & & $\begin{array}{l}\text { Guia de Aplicação Versões da marca, } \\
\text { Padrões cromáticos RGB, CMYK e Pantone, } \\
\text { Padrão tipográfico, Aplicações sobre fundos } \\
\text { de cor e Reduções. (i3s1) }\end{array}$ \\
\hline & & Displays para lojas 20 de cada. (i2s6) \\
\hline & \multirow{3}{*}{$\begin{array}{l}\text { 6.2 Prazo } \\
\text { Caracterização da } \\
\text { temporalidade do } \\
\text { projeto }\end{array}$} & Prazo ideal de apresentação: 01/07. (i5s1) \\
\hline & & 14h [nome do cliente] PDV. (i2s9) \\
\hline & & Se urgente, especifique o motivo: (i5s1) \\
\hline & \multirow{3}{*}{$\begin{array}{l}\text { 6.3 Financeiro } \\
\text { Caracterização } \\
\text { dos parâmetros } \\
\text { econômicos do } \\
\text { projeto }\end{array}$} & Verba. (i5s1) \\
\hline & & $120 \mathrm{~K}-150 \mathrm{~K}$ prod \& mid. (i2s12) \\
\hline & & $\begin{array}{l}\text { Valor de investimento baixo; Rentabilidade } \\
\text { clara; (i6s1) }\end{array}$ \\
\hline \multirow{3}{*}{\multicolumn{2}{|c|}{$\begin{array}{l}7 \text { Síntese } \\
\text { Informações resumidas do que se espera do } \\
\text { projeto }\end{array}$}} & Resumo da tarefa a ser realizada. (i1s1) \\
\hline & & $\begin{array}{l}\text { Defina em uma ou duas frases qual o sonho/ } \\
\text { expectativa do cliente em relação a este } \\
\text { projeto. (i1s1) }\end{array}$ \\
\hline & & O que a empresa faz - em uma frase. (i3s2) \\
\hline
\end{tabular}

Fonte: Elaborado pelos autores.

A categoria 'Orientações gerais' apresenta informações que tratam de aspectos ampliadores do espaço de discussão do projeto e que podem, ou não, refletir no projeto em si - estão no campo das possibilidades. Esta categoria se divide em 1.1) 'Contextualização mercadológica', 1.2) 'Considerações criativas' e 1.3) 'Ideias propostas'.

'Contextualização mercadológica' apresenta informações relacionadas ao contexto de atuação do demandante do projeto, representado pelas unidades "Para conduzirmos a criação, é necessário conhecer mais a empresa" (i4s4) e "Mercado em que o cliente atua" (i1s1). Ainda, nesta subcategoria, tratam-se aspectos relativos a expectativas mercadológicas do projeto, representadas pela unidade "Devemos colaborar para que o mercado total aumente nos primeiros 6 meses em ........\%?" (i1s1). 
'Considerações criativas' apresenta informações relacionadas a possibilidades, isto é, subsídios que de alguma forma poderão gerar ideias no projeto, representada pelas unidades "Pensar bem nas poses [...] procuraram [nome da marca considerada referência] modelo sem calço [...] cuidar logo [...]" (i2s8), "[...] pensei em colocar a safra no selo que vai por cima da capsula no gargalo da garrafa" (i4s1) e "Visual feminino, elegante, festivo e minimalista, que surpreenda e encante o público através do cuidado e de detalhes diferenciados." (i3s2).

'Ideias propostas' apresenta informações relacionadas a ideias materializadas no briefing para ser consideradas no projeto, representada pelas unidades "Foi cogitado desenhar na arte da caixa, uma "Estrada" ou "Caminho" em curva, com vários objetos antigos e novos, por exemplo [...] Telefone antigo e celular, TV antiga e computador." (i4s4) e "esta franquia não dá dor de cabeça' é fácil - conceito para produzir um remédio contra os concorrentes de franquias difíceis." (i6s1)

A categoria 'Grau de imprescindibilidade' apresenta informações que tratam de aspectos diretamente relacionados ao projeto, e que imprescindivelmente devem ser considerados em seu processo. Difere de 'Orientações gerais', que atua no campo das possibilidades, pois 'Grau de imprescindibilidade' atuam no campo das obrigatoriedades, precisando necessariamente refletir no projeto o que trata. Esta categoria se divide conforme o grau, em 2.1) 'Importante', 2.2) 'Obrigatório' e 2.3) 'Limitações'.

'Importante' traz informações que ressaltam um dever, em tom de alerta, do que deve ser levado em consideração no processo de projeto, com se identifica nas unidades "É importante não usar imagens "estereotipadas" de idosos. [..]" (i4s4) e "Precisamos colocar benefícios que [o cliente] proporciona para os franqueados - Treinamento contínuo; Suporte criativo no projeto, implementação e execução da loja;" (i6s1) que compõem esta subcategoria.

'Obrigatório', por sua vez, também ressaltam um dever. Porém mais do que alertar, sinalizam não haver espaços para questionamentos - é obrigação que o processo de projeto contemple estas informações presentes no briefing É representada por unidades explicitas como "Textos obrigatórios" (i1s1), e em unidades com verbos no imperativo como "vamos escrever no rótulo [marca do cliente]" (i4s1)

'Limitações', em um sentido oposto (mas não menos limitante que 'Obrigatório') trata de deveres relacionados a incapacidade ou impossibilidade de que algo esteja presente no processo de projeto, e que tal situação precisa ser considerada. É representada pelas unidades "Limitações e obrigatoriedades" (i5s1), "Existem restrições?" (i1s1).

As categorias 'Problema' e 'Objetivos e expectativas' apresentam proximidades com as subcategorias tratadas em 'Orientações gerais' e 'Grau 
de imprescindibilidade', afinal há uma relação muito íntima entre os deveres do projeto, suas problematizações expostas e os objetivos que lhe interessam. Separam-se, nesta análise de conteúdo, porque nominalmente são unidades que declaram 'Problema' ou 'Objetivos e expectativas'. Enquanto 'Problema' é representado pelas unidades "Cenário/problema" (i5s1), "Problema: precisamos pensar em que tipo de peças de comunicação podemos produzir para venda de franquia [nome do cliente]" (i6s1), Objetivos' ou 'Expectativas' é representado por "Objetivo: expansão do mercado franchising das lojas físicas da [marca do cliente] [...]" (i6s1) e "Objetivos: quais as expectativas do cliente em relação a campanha e cada peça?" (i1s1).

A categoria 'Actantes' apresenta informações que tratam de quem o briefing advoga como porta-voz e que, junto com ele, compõem a rede sociotécnica construída em torno do processo de projeto. Esta categoria dividese pelas actancialidades em 5.1) 'Responsável', 5.2) 'A quem se destina o fato ou artefato' e 5.3) 'Terceiros'.

'Responsável' é representado por unidades que indicam quem é o ponto focal que deu origem a demanda de projeto - ou ao menos a quem se deve recorrer quando o briefing não for capaz de responder as dúvidas. "Responsável" (i1s1), "Responsável pelo pedido" (i5s1), "Contato: Salete" (i4s4) exemplificam esta subcategoria.

'A quem se destina o fato ou artefato' merece atenção pela escolha de termo: nesta pesquisa não se faz uso do termo comum do design (usuário), por considerá-lo restritivo a quem faz uso, delimitado a um papel passivo a quem interessa, ou deveria interessar, o fato ou artefato gerado. Trata-se aqui de 'a quem se destina' porque estes actantes são entendidos como entidades cujas relações mediadas com estes fatos e artefatos vão além dos normativos. As unidades que representam esta subcategoria tomam forma de enunciados como "Defina hábitos e atitudes dos consumidores em relação ao produto" (i1s1) e "Quem vai receber esse material é o público ( ) interno ( ) externo" (i5s1) ou descrições mais amplas como "O público alvo é prioritariamente masculino, porém amplo - dos diretores das empresas aos operadores de máquinas. O contato comercial é realizado com diretores e gerentes" (i3s1).

Por fim a subcategoria 'Terceiros' traz unidades que representam a multiplicidade dos actantes envolvidos nesta rede sociotécnica representativa do projeto, desde os que auxiliam a viabilizar o projeto com ajuda instrumental como apresentado na unidade "A gráfica que imprime as peças é a [nome empresa] de São Paulo, e o contato é o Luciano" (i4s4) aos que moldam o projeto por comparação, como nas unidades "Benchmark: The TomKat Studio, Mog \& Um, Lia Griffith e HWTM" (i3s2).

A penúltima categoria, 'Especificações técnicas', apresenta informações que tratam de especificidades do projeto, esmiuçando o que deve 
ser considerado no seu processo no tange aspectos técnicos. Esta subcategoria se divide em 6.1) 'Detalhamento', 6.2) 'Prazo' e 6.3) 'Financeiro'.

'Detalhamento' apresenta informações que tratam de a prioris do próprio processo de projeto, com intenções de dimensionar de alguma forma seu comportamento e, em alguns aspectos, representam possíveis situações vividas que geraram um interesse em 'enquadrar' o que o que está em jogo, em uma lógica de eficiência e produtividade nos moldes Taylor fordistas. Como unidades representativas, podem-se destacar "Quais as peças que devem ser desenvolvidas, quais as especificações técnicas e formatos?" (i1s1), "Guia de Aplicação: Versões da marca, Padrões cromáticos RGB, CMYK e Pantone, Padrão tipográfico, Aplicações sobre fundos de cor, Reduções" (i3s1), ou unidades que tratam de quantidade ou formas de entrega de arquivos, como "Displays para lojas 20 de cada" (i2s6).

'Prazo' apresenta informações que tratam das temporalidades do processo de projeto, seguindo a mesma lógica de enquadramento, eficiência e produtividade descritas na subcategoria 'Detalhamento'. As unidades "Prazo ideal de apresentação: 01/07" (i3s1), "20 de nov. Embalagem" (i2s7) e "14h [nome do cliente] PDV" (i2s9) tratam de esclarecimentos diversos acerca das temporalidades envolvidas, enquanto a unidade "Se urgente, especifique o motivo:" (i5s1) traz um outro aspecto relacionado a temporalidade: que as urgências precisam de justificativas, uma vez que tendem a prejudicar outros processos projetuais.

A subcategoria 'Financeiro' apresentam informações que parametrizam economicamente o projeto, sendo representadas pelas unidades "Verba" (i5s1), "Qual a verba destinada para cada peça?" (i1s1) e "120K - 150K prod \& mid" (i2s12) ou ainda uma ampliação quanto a percepção de valor, como em "Valor de investimento baixo; Rentabilidade clara;" (i6s1).

E encerrando a análise de conteúdo do quadro 'Informações', a última categoria, 'Síntese', apresenta informações resumidas ou cujas locuções intencionam a simplificação do projeto ao máximo. Sem subcategorias, é representada pelas unidades "resumo da tarefa a ser realizada" e "Defina em uma ou duas frases qual o sonho/expectativa do cliente em relação a este projeto" (ambas do i1s1) e "O que a empresa faz - em uma frase" (i3s2).

\section{DISCUSSÃO}

A seção de discussão concentra-se em 2 grandes tópicos derivados da análise do quadro 'Informações': a pluralidade das materializações do briefing e seu caráter plástico, de actancialidades evocativas, mediadoras de interesses relacionados ao processo de projeto. 
O primeiro aspecto refere-se à pluralidade de materializações do briefing. Apesar de carregar em si fechamentos específicos, como se evidência em 'Especificações técnicas', ele é mais do que isso: media-se conforme o que é pertinente ao projeto ao qual participa, demonstrando uma plasticidade associativa irredutível a um único modelo - ou seja, apesar do senso comum enxergá-lo como documento que lista, ao dar zoom in em como ele é torna-se impossível reduzi-lo a um único modelo de briefing.

O segundo aspecto a destacar é que, ao compreendê-lo como actante que media associações, entende-se que ele não só se media ao processo (caráter plástico), media o processo em si. A partir dos suportes recebidos (o briefing enquanto uma pontualização), é possível expandir e enxergar os movimentos propostos para que a associação em torno do processo de projeto se estabilize. Ou seja, o briefing enquanto actante, opera nesta associação, com competências particulares de mediar interesses. Mediar é estar entreposto, em movimentos orientados pela estabilização, associando questões de preocupação múltiplas e abertas - tais como os problemas de design ou os interesses de outros actantes, por exemplo.

Neste sentido, entende-se o briefing enquanto algo que acompanha e provoca as modificações as quais o processo de projeto passa, sendo incorporado aos novos contextos surgidos ao longo dele. Compreendê-lo enquanto um mediador dos interesses, neste sentido, parece pertinente por denotar a actancialidade que ele tem de acompanhar as dinâmicas e os novos contextos surgidos, uma que vez que é entendido como algo que acrescenta e modifica as associações que contingenciam o processo de projeto. Mesmo que em suas materializações guarde aspectos de intermediação (ao listar requisitos, como as categorias apontam), a compreensão dele enquanto mediador é evidenciada nesses movimentos que vão além de determinismos, isto é, mesmo enquanto listagem, oscila entre restringir e ampliar o processo de projeto pelo tipo de perguntas que faz, fazendo emergir questões de preocupação múltiplas. Desta forma, mesmo quando supõe fechamentos - ao dizer claramente a verba, por exemplo - o briefing apresenta actancialidades evocativas que ampliam o processo de projeto (seja tratando de contextos mercadológicos, seja trazendo considerações criativas e ideias propostas) deslocando o processo de projeto para um espaço além do normativo, mas das possibilidades.

Neste sentido, o briefing, assim como os estudos em design, permitem ampliar a própria perspectiva desta pesquisa: escapam de uma lógica científica de bases modernas, em que há uma crença de que a partir de teorias e métodos aplicáveis seja capaz de obter resultados satisfatórios - o design, como ciência, é envolvido, situado e integrado, contingenciando os contextos projetuais aos quais se dispõe a tratar. Isto não significa uma abominação as teorias e métodos, mas uma compreensão que sua processualidade é outra, e que a abertura às incertezas dos contextos a se investigar é condição à sua realização (FINDELI, 2001). 
Assim, esta pesquisa abandona a lógica normativa de que o briefing é algo que explicita o que deve ser feito, mas é algo que evoca actancialidades do processo de projeto, fomentando a reflexão acerca dos pontos aos quais o projeto deverá estar sensível e atento ao mediar os interesses.

\section{AGRADECIMENTOS}

Os autores agradecem a CAPES/PROSUC pela bolsa integral de Mestrado concedida a um dos pesquisadores.

\section{REFERÊNCIAS}

ASSOCIAÇÃO DOS DESIGNERS GRÁFICOS DO BRASIL. ADG BRASIL. O valor do design: guia ADG Brasil de prática profissional do designer gráfico. São Paulo: SENAC, 2004.

BINDER, Thomas et al. Democratic design experiments: between parliament and laboratory. CoDesign, London, v. 11, n. 3-4, p. 152-165, 2015.

BJÖRGVINSSON, Erling; EHN, Pelle; HILLGREN, Per-Anders. Participatory design and "democratizing innovation". In: PARTICIPATORY DESIGN CONFERENCE, 11., 2010, Sydney. Anais... Ney York: ACM, 2010. p. 41-50.

BROWN, Tim. Change by design: how design thinking transforms organization and inspires innovation. New York: HarperCollins, 2009.

BUCHANAN, Richard. Wicked problems in design thinking. Design issues, Illinois, v. 8, n. 2, p. 5-21, 1992.

BUCHANAN, Richard. Worlds in the making: design, management, and the reform of organizational culture. She Ji: The Journal of Design, Economics, and Innovation, Shangai, v. 1, n. 1, p. 5-21, 2015.

CALLON, Michel. Some elements of a sociology of translation: domestication of the scallops and the fishermen. The Sociological Review, Oxford, v. 32, p. 196-233, May 1984.

FINDELI, Alain. Rethinking design education for the 21st century: theoretical, methodological, and ethical discussion. Design Issues, Cambridge, v. 17, n. 1, p. 5-17, 2001.

KRIPPENDORFF, Klaus. Content analysis: an introduction to its methodology. Thousand Oaks: Sage, 2012.

LATOUR, Bruno. On actor-network theory: a few clarifications. Soziale Welt, Baden-Baden, v. 47, p. 369-381, 1996.

LATOUR, Bruno. On recalling ANT. The Sociological Review, Oxford, v. 47, n. 1, p. 15-25, 1999. 
LATOUR, Bruno. Reassembling the social: an introduction to actor-networktheory. Oxford: Oxford University Press, 2005.

LATOUR, Bruno. Science in action: how to follow scientists and engineers through society. Cambridge: Harvard University Press, 1987.

LATOUR, Bruno. What is the style of matters of concern: two lectures in empirical philosophy. Amsterdam: Van Gorcum, 2008.

LAW, John. After ANT: complexity, naming and topology. The Sociological Review, Oxford, v. 47, n. 1, p. 1-14, 1999.

LAW, John. Notes on the theory of the actor-network: ordering, strategy, and heterogeneity. Systems Practice, New York, v. 5, n. 4, p. 379-393, 1992.

BRIEFING. In: Merriam-Webster. Disponível em: <https://www.merriamwebster.com/dictionary/briefing>. Acesso em: 24 jul. 2016a.

BRIEFING. In: Oxford dictionaries. Disponível em: <https:// en.oxforddictionaries.com/definition/briefing>. Acesso em: 24 jul. $2016 \mathrm{~b}$.

RITTEL, Horst Willhelm Jakob; WEBBER, Melvin Myron. Dilemmas in a general theory of planning. Policy Sciences, Amsterdam, v. 4, n. 2, p. 155-169, 1973.

SÁ-SILVA, Jackson Ronie; ALMEIDA, Cristóvão Domingos de; GUINDANI, Joel Felipe. Pesquisa documental: pistas teóricas e metodológicas. Revista Brasileira de História \& Ciências Sociais, Santa Vitória do Palmar, v. 1, n. 1, p. 1-15, 2009. Disponível em: <https://www.rbhcs.com/rbhcs/article/view/6/ pdf $>$. Acesso em: 30 jul. 2016.

SAYES, Edwin. Actor-network theory and methodology: just what does it mean to say that nonhumans have agency? Social Studies of Science, London, v. 44, n. 1, p. 134-149, 2014.

STORNI, Cristiano et al. Designing things together: intersections of co-design and actor-network theory. CoDesign, London, v. 11, n. 3-4, p. 149-151, 2015.

ZURLO, Francesco. Design strategico. Treccani. 2010. Disponível em: <http:// www.treccani.it/enciclopedia/design-strategico_\%28XXI-Secolo\%29/>. Acesso em: 30 abr. 2014. 